\title{
A DESPECUNIARIZAÇÃO NA RESPONSABILIDADE CIVIL A PARTIR DO FILME AQUARIUS: TUTELA INIBITÓRIA E COMPENSAÇÃO IN NATURA DE DANOS MORAIS
}

\author{
THE DEMONETIZATION IN TORT LIABILITY FROM THE FILM \\ AQUARIUS: INJUNCTION AND IN NATURA COMPENSATION OF \\ MORAL DAMAGES
}

\author{
Rafael Marcílio Xerez \\ Universidade de Fortaleza - Unifor - (Fortaleza, CE, Brasil) \\ Márcio Anderson Silveira Capistrano \\ Universidade de Fortaleza - Unifor - (Fortaleza, CE, Brasil)
}

Recebimento: 20 jun. 2018

Aceitação: 23 jul. 2018

\begin{abstract}
Como citar este artigo / How to cite this article (informe a data atual de acesso / inform the current date of access):
XEREZ, Rafael Marcílio; CAPISTRANO, Márcio Anderson Silveira. A despecuniarização na responsabilidade civil a partir do filme Aquarius: tutela inibitória e compensação in natura de danos morais. Revista da Faculdade de Direito UFPR, Curitiba, PR, Brasil, v. 63, n. 2, p. 191-211, ago. 2018. ISSN 2236-7284. Disponível em: <https://revistas.ufpr.br/direito/article/view/60047>. $\quad$ Acesso $\quad$ em: $30 \quad$ ago. $2018 . \quad$ DOI:
\end{abstract} http://dx.doi.org/10.5380/rfdufpr.v63i2.60047.

\section{RESUMO}

A partir do drama vivenciado pela personagem Clara no filme Aquarius (2016), o presente artigo objetiva caracterizar os excessos da monetarização no enfrentamento aos danos morais e indicar alternativas jurídicas aplicáveis no ordenamento jurídico brasileiro, com lastro no exame da doutrina especializada e de decisões judiciais. Caracterizada a tendência de prevenção de danos e tutela específica das obrigações, examina-se a viabilidade da ação inibitória como remédio processual para garantir o sossego domiciliar em face de vizinhos. Ademais, verifica-se a plausibilidade jurídica da tese da compensação in natura de danos morais, mesmo na ausência de autorização expressa em lei. Conclui-se que, preventivamente, é preciso garantir a ação inibitória para defender interesses existenciais e que, após a ocorrência do dano moral, é salutar que a compensação pecuniária seja associada a meios despecuniarizados de reparação, como o pedido público de desculpas, a fim de efetivamente fazer frente ao prejuízo moral na mesma seara em que foi experimentado.

\section{PALAVRAS-CHAVE}

Responsabilidade civil. Danos morais. Tutela inibitória. Despecuniarização. Direito e cinema.

\section{ABSTRACT}

Taking as a starting point the drama experienced by the character Clara from the film Aquarius (2016), this article aims to characterize the excesses of monetization in compensation of moral damages and to indicate legal alternatives applicable in Brazilian law, based on the exam of specialized doctrine and judicial decisions. After characterizing the tendency of prevention of damages and specific protection of obligations, it is analyzed the viability of the injunction as a 
procedural remedy to guarantee home placidity in the face of neighbors. In addition, it is verified the legal plausibility of the theory of in natura compensation of moral damages, even in the absence of express authorization in legal statutes. It is concluded that preventive action must be taken in order to defend existential interests and that, after the occurrence of moral damages, it is salutary that pecuniary compensation be associated with demonetized means of redress, such as public apology, in order to effectively cope with the moral prejudice in the same field it was experienced.

\section{KEYWORDS}

Tort liability. Moral damages. Injunction. Demonetization. Law and cinema.

\section{INTRODUÇÃO}

A atividade hermenêutica contemporânea demanda que, a par do direito legislado, seja conferido o devido peso às dimensões fática e axiológica do fenômeno jurídico. Como é cediço, a criação de norma jurídica não se resume à mera declaração de um direito previamente estabelecido, tendo em vista que, no processo de interpretação, ressalta-se a importância da formulação de juízos de valor sob a influência da história, das experiências de vida e das compreensões acerca da realidade por parte do intérprete-concretizador.

Especialmente na análise de casos concretos que envolvem responsabilidade civil, é frequente a constatação de que o conjunto de textos normativos disponíveis no ordenamento jurídico se mostra insuficiente ou em descompasso com os desafios da contemporaneidade, ou seja, com a tutela jurídica adequada de novas situações subjetivas ou novos direitos.

No contexto de compensação de danos morais, verifica-se que o alargamento das fronteiras da definição de dano indenizável e a ampliação dos casos de responsabilização, embora signifiquem maior proteção às vítimas, impulsionam tendências de litigiosidade e vitimização, com o estímulo a demandas judiciais frívolas, assim como às denominadas “cultura da culpabilização” (blame culture) e "loteria dos danos” (damages lottery), expressões críticas consagradas por Patrick Atiyah (1997). A esse cenário soma-se a mercantilização na resposta do sistema jurídico a danos morais, com a ocorrência de exageros e deturpações a caracterizar o que comumente se aponta como “indústria dos danos morais".

Tendo como ponto de partida o drama vivenciado pela personagem Clara no filme Aquarius (2016), o presente artigo objetiva caracterizar os excessos da monetarização no enfrentamento aos danos morais e indicar alternativas jurídicas aplicáveis no ordenamento jurídico brasileiro, com lastro no exame da doutrina especializada e de decisões judiciais. Desse modo, com base na tendência de prevenção de danos e tutela específica das obrigações, examina-se a viabilidade da ação inibitória como remédio processual para garantir o sossego domiciliar em face de vizinhos. Ainda, investiga- 
se a viabilidade jurídica da tese da compensação in natura de danos morais, mesmo na ausência de autorização expressa em texto legal.

\section{O FILME AQUARIUS COMO MOTE DO ESTUDO: A FORÇA DRAMÁTICA DA SITUAÇÃO DE CLARA E A EFETIVIDADE DA TUTELA JURÍDICA DE INTERESSES EXISTENCIAIS}

De início, observa-se que arte e ciência não devem ser segregadas como campos de atuação humana incomunicáveis, tendo em vista que a análise interdisciplinar dos fenômenos sociais permite ao jurista uma compreensão mais complexa e rica, especialmente em temáticas mais sensíveis atinentes à honra, à dignidade, à dor.

Quanto ao direito na arte, Rafael Xerez (2014, p. 236) sublinha que obras de arte, embora não tratando de tema especificamente referente à aplicação do direito, são capazes de fazer o jurista refletir sobre bens e valores tradicionalmente qualificados juridicamente como direitos, como no enfrentamento de questões relativas à vida, à liberdade, à honra, à maternidade, entre tantos outros bens e valores significativos para a pessoa humana.

Nesse sentir, vem se afirmando progressivamente o movimento Law and Cinema (ou Law and Film), iniciado no final da década de 1980 no contexto da educação jurídica, a partir da consideração de que ambos convivem no mesmo ambiente sociocultural e que, assim, exercem entre si influência recíproca, de modo a permitir que se adicione um aspecto personalizado à reflexão jurídica, para torná-la mais humana, específica e significativa (KAMIR, 2005, p. 255-256, 275). Aliás, Giddens (1991, p. 24) observa que existe entre as ciências sociais e seus objetos uma relação reflexiva de "hermenêutica dupla", com o desenvolvimento do conhecimento a partir de conceitos leigos dos agentes, tendo em vista que “[o] conhecimento sociológico espirala dentro e fora do universo da vida social, reconstituindo tanto este universo como a si mesmo como uma parte integral deste processo".

O intercâmbio direito-cinema pode ser expressado por uma pluralidade de perspectivas, como, por exemplo, um “olhar jurídico” que interprete a realidade à luz do universo do direito ou, de outro lado, um “olhar sensível” sobre problemas jurídicos que, alimentado pela experiência estética proporcionada pela obra cinematográfica, busque novas formas de compreender o próprio direito (MARTINEZ, 2015, p. 71-73). Sobre a contribuição do cinema para o direito e o campo de estudo “Direito e Cinema”, vale conferir:

As narrativas jurídicas e cinematográficas fornecem um significado para eventos - ordinários

e extraordinários - que são prontamente interpretados. São relatos paradigmáticos, 
experiências de casos ou histórias que infundem interações sociais contextualizadas. Estas estruturas narrativas são frequentemente realizadas (e culturalmente mantidas) através de símbolos visuais, audiovisuais, sinais e anotações; representações que trazem um conjunto de conotações cognitivas e emotivas. Estes quadros narrativos participam na formação das convenções sociais desempenhando um importante papel na formação da pessoa, da identidade do grupo e da memória coletiva. Além disso, desempenham um papel na formulação de certas posições morais: é contra certas histórias paradigmáticas que nos tornamos conscientes daquilo que estamos defendendo; é contra essas histórias que aprimoramos nosso senso de justiça e determinamos o que é certo ou errado (CESTARI; NOJIRI, 2015, p. 185).

A compreensão de que o direito se insere no domínio da cultura enseja que as práticas expressivas vizinhas sejam levadas a sério na formação da consciência leiga e profissional do jurista, assim como na compreensão dos papéis dentro do sistema social e das expectativas da sociedade diante do direito (REICHMAN, 2008, p. 462). A linguagem cinematográfica, ao despertar emoções e conhecimento na experiência estética vivenciada, proporciona uma compreensão mais verticalizada dos temas humanísticos discutidos, a partir do estímulo às capacidades criativas do espectador, a ensejar a construção de novas perspectivas críticas e soluções para problemas em aberto.

Estabelecidas essas premissas, passa-se ao exame do longa-metragem Aquarius, cuja sinopse é a seguinte: Clara, interpretada pela atriz Sônia Braga, mora em um apartamento localizado no litoral da cidade pernambucana do Recife, no prédio homônimo ao filme, onde viveu com sua família boa parte de sua vida. Interessados em erguer um novo edifício mais moderno no mesmo terreno, os responsáveis por uma construtora conseguem adquirir quase todas as unidades do prédio, à exceção daquele em que mora a protagonista. Embora deixe bem claro que não deseja realizar a venda, Clara passa a sofrer diversas investidas de assédio e ameaça, para que mude de posição.

O roteiro preocupa-se em eleger cenas carregadas de emotividade, a serviço de potencializar a carga dramática do conflito vivenciado por Clara. A cada pequena história contada, o espectador passa a aprofundar-se no universo de Clara e compreender cada vez mais sua relação de afeto com o apartamento onde vive, palco de momentos centrais de sua história e refúgio diante do desafio de enfrentar a rotina de uma senhora viúva cujos filhos já saíram de casa.

Clara é uma senhora ainda formosa, que construiu sua carreira no meio artístico e, até o início das ofensivas da construtora, levava uma existência tranquila cercada por seus discos e livros, com a rotina de passear na praia todas as manhãs. A trama visita eventos como festas de família, bailes frequentados por pessoas idosas e conversas familiares na sala de estar, a extrair doçura das relações entre pessoas ligadas por suas memórias em comum.

Acerca da relação emotiva de Clara com o apartamento e com suas recordações, são precisas as ponderações do crítico de cinema Pablo Villaça (2016): 
Esta, afinal, é a natureza de nossas memórias, que conferem peso e significado diferentes para tudo que nos cerca: um piano, por exemplo, não é só um instrumento, mas traz consigo um pedaço de todos que já o tocaram e as ocasiões em que o fizeram [...]. É por esta razão que a personagem de Braga valoriza tanto a fisicalidade de um disco: não é que seja avessa às novas tecnologias e se recuse a ouvir canções em mp3 (ela não se recusa); o problema é que não é possível tocar um arquivo digital com as mãos e pensar em todos que já o carregaram ou então comprá-lo em um sebo e adquirir, com ele, sua história e tudo o que traz de abstrato, como lembranças, sentimentos e signos.

É isto que aqueles que querem derrubar o prédio-título não compreendem: embora acreditem estar fazendo uma oferta "generosa” para comprar o apartamento de Clara, não computam e nem teriam como computar - o valor das memórias que este abriga.

A oferta da construtora para que Clara saia do prédio é de dois milhões de reais, valor considerado pelos demais personagens como generoso. Todavia, para a protagonista, o dinheiro não importa, seja porque conseguiu alcançar um padrão de vida bastante confortável como fruto do seu sucesso profissional, seja porque, na altura da vida em que se encontra, seu interesse consiste em prosseguir com sua rotina serena e terminar seus dias em paz.

O roteiro vai construindo uma tensão entre Clara e todos à sua volta: a construtora, sua família, seus antigos vizinhos. O posicionamento da última moradora do prédio é tido como teimosia e egoísmo pelos demais, que não conseguem entender a motivação da personagem. Clara passa, então, a sofrer pressão, em escala crescente, de várias pessoas, especialmente por parte do responsável pelo empreendimento imobiliário.

A obra cinematográfica faz uso de uma metáfora, que se revela mais claramente ao final do filme: Clara venceu um câncer na juventude e, agora, está disposta a se tornar um câncer para seus inimigos. A protagonista não aceita as opressões que lhe são impostas. Resiste com dignidade e bravura, em defesa de seus interesses existenciais mais caros.

O conflito vivenciado por Clara goza de uma inegável força expressiva e simbólica, a proporcionar ao jurista uma experiência estética capaz de fazer compreender que, em determinadas situações da vida, o dinheiro tem pouca relevância. Qualquer tentativa de apenas estabelecer vantagem pecuniária em favor de Clara, na forma de compensação por danos morais, não seria capaz de tutelar efetivamente seu direito: para a personagem, importava apenas uma resposta jurídica que lhe garantisse o mínimo para uma existência digna e pacífica dentro de seu próprio domicílio.

Clara chega a conversar com um advogado no filme, logo após a primeira tentativa amigável da construtora de comprar o apartamento. Na ocasião, a protagonista ouviu que nada poderia ser feito, pois nada havia acontecido além de uma conversa consentida, ainda que desagradável, na entrada do apartamento. Depois, diante das ameaças e abusos sofridos ao longo da trama, a personagem acaba buscando resolver seu problema por outras vias. Mas cabe questionar: a resposta do advogado teria sido diferente após as demais investidas da construtora? O direito seria capaz de oferecer uma solução 
para o drama de Clara? O que o filme tem a contribuir no debate sobre a despecuniarização na responsabilidade civil?

\section{O SOSSEGO DOMICILIAR COMO DIREITO DA PERSONALIDADE E A TUTELA INIBITÓRIA}

Em seu domicílio, cada pessoa terá condições de exercer sua intimidade, de forma a permitir o pleno desenvolvimento de sua personalidade e suas respectivas potencialidades latentes. Tal exercício propiciará a busca pela felicidade, objetivo de todo ser humano.

Como é cediço, a inviolabilidade da intimidade e da vida privada possuem guarida constitucional, assim como a inviolabilidade do domicílio ${ }^{1}$. A proteção constitucional ao domicílio tutela a intimidade da pessoa humana, exercida naquele espaço destinado à sua moradia. Nessa toada, Lord Chatam proferiu seu célebre discurso perante o Parlamento inglês:

O homem mais pobre desafia em sua casa todas as forças da Coroa, sua cabana pode ser muito frágil, seu teto pode tremer, o vento pode soprar entre as portas mal ajustadas, a tormenta pode nela penetrar, mas o Rei da Inglaterra não pode nela entrar (SILVA JUNIOR, 2008, p. 5).

Útil, ainda, pontuar que o direito de moradia, constituindo um bem irrenunciável das pessoas, abrange diversas manifestações referentes à proteção da personalidade, pois guarda relação intrínseca com os conceitos de integridade física, integridade psíquica e integridade moral; ademais, caracterizando-se como bem extrapatrimonial, não necessariamente recai sobre a figura do proprietário, considerando que as pessoas podem exercer sua moradia, por exemplo, a partir de relação contratual de locação residencial ou comodato (SOUZA, 2009, p. 189, 396).

Em Aquarius, o responsável pela construtora exerce os poderes de propriedade dos demais apartamentos do prédio de forma emulativa, com o propósito de prejudicar Clara e forçá-la a deixar o local, a configurar abuso de direito e malferir disposições do Código Civil ${ }^{2}$. Sobre o ponto, colhese o ensinamento basilar de Nelson Hungria (1958, p. 261) ao tratar do crime de inviolabilidade de

\footnotetext{
${ }^{1}$ Dispõe o artigo 5º X, da Constituição Federal: “são invioláveis a intimidade, a vida privada, a honra e a imagem das pessoas, assegurado o direito a indenização pelo dano material ou moral decorrente de sua violação”. Por sua vez o artigo $5^{\circ}$, XI, da Constituição Federal confere especial proteção à inviolabilidade do domicílio: “a casa é asilo inviolável do indivíduo, ninguém nela podendo penetrar sem consentimento do morador, salvo em caso de flagrante delito ou desastre, ou para prestar socorro, ou, durante o dia, por determinação judicial”.

${ }^{2}$ Art. 1.228, § $2^{\circ}$ : “São defesos os atos que não trazem ao proprietário qualquer comodidade, ou utilidade, e sejam animados pela intenção de prejudicar outrem”. Art. 187: “Também comete ato ilícito o titular de um direito que, ao exercêlo, excede manifestamente os limites impostos pelo seu fim econômico ou social, pela boa-fé ou pelos bons costumes”. Somam-se, ainda, os comandos dos artigos 1.277 e seguintes, que tratam do uso anormal da propriedade dentro das regras de direito de vizinhança.
} 
domicílio: “O exercício de um direito degenera em abuso e torna-se atividade antijurídica, quando invade a órbita de gravitação do direito alheio”.

Nesse contexto, é certo que o direito fundamental à tutela jurisdicional efetiva, previsto no artigo $5^{\circ}$, inciso XXXV, da Constituição, abrange, na hipótese de direito extrapatrimonial, o direito a uma tutela apta a impedir a violação do direito, o que se torna indispensável em um ordenamento cuja unidade axiológica encontra-se na dignidade da pessoa humana, pois a garantia de apreciação de “ameaça a direito” pelo Estado-juiz representa compromisso real (e não meramente retórico) com a inviolabilidade dos direitos da personalidade (MARINONI, 2004, p. 82).

Afinal, não seria possível pensar em direito à honra ou à intimidade sem tutela inibitória, já que afirmar a inviolabilidade de um direito somente faz sentido se for prevista no ordenamento jurídico uma forma de tutela capaz de impedir essa violação, e “alguns dos direitos mais fundamentais - entre os quais os direitos personalíssimos - não podem ser satisfeitos por mera proteção repressiva, a posteriori, por recomposição patrimonial (mesmo porque não têm o conteúdo patrimonial)” (ARENHART, 2003, p. 219).

O Código Civil trouxe, nos artigos 11 e seguintes, disposições sobre os direitos da personalidade, como a honra, o nome, a imagem, a privacidade, o respeito e a inviolabilidade do domicílio. O Codex preocupou-se em estabelecer não apenas uma tutela reparatória de danos ocorridos, mas, especialmente, uma tutela preventiva, mais desejável do que a indenização em dinheiro após a ocorrência do dano:

Art. 12. Pode-se exigir que cesse a ameaça, ou a lesão, a direito da personalidade, e reclamar perdas e danos, sem prejuízo de outras sanções previstas em lei.

[...]

Art. 21. A vida privada da pessoa natural é inviolável, e o juiz, a requerimento do interessado, adotará as providências necessárias para impedir ou fazer cessar ato contrário a esta norma. (grifos nossos).

Os direitos da personalidade devem ser interpretados como expressão da cláusula geral de tutela da pessoa humana, lastreada no valor da dignidade da pessoa humana, em cujo cerne encontram-se a igualdade, a integridade psicofísica, a liberdade e a solidariedade (MORAES, 2003, p. 127-128). Nessa esteira, impende garantir não apenas que um dano sofrido seja compensado, mas também que se possa impedir ou fazer cessar atividade ilícita. O tradicional pensamento voltado ao aspecto repressivo da responsabilidade civil, com o dever de compensar os danos morais, deve ser ponderado com a tendência contemporânea da atuação preventiva do direito no sentido da preservação e efetiva tutela dos direitos da personalidade, com o objetivo de evitar a ocorrência do dano, a demonstrar a importância da tutela específica nos tempos atuais. 
A proteção aos direitos da personalidade pode ser buscada por meio da propositura da ação inibitória, instrumento expressamente previsto no art. 497 do novo Código de Processo Civil:

Art. 497. Na ação que tenha por objeto a prestação de fazer ou de não fazer, o juiz, se procedente o pedido, concederá a tutela específica ou determinará providências que assegurem a obtenção de tutela pelo resultado prático equivalente.

Parágrafo único. Para a concessão da tutela específica destinada a inibir a prática, a reiteração ou a continuação de um ilícito, ou a sua remoção, é irrelevante a demonstração da ocorrência de dano ou da existência de culpa ou dolo. (grifo nosso).

A tutela inibitória constitui tutela específica, na medida em que tem por objetivo conservar a integridade do direito, e assume acentuada relevância na proteção de direitos da personalidade,

não apenas porque alguns direitos não podem ser reparados e outros não podem ser adequadamente tutelados através da técnica ressarcitória, mas também porque é melhor prevenir do que ressarcir, o que equivale a dizer que no confronto entre a tutela preventiva e a tutela ressarcitória deve-se dar preferência à primeira (MARINONI, 2006, p. 38).

A fruição in natura do direito constitui o fundamento axiológico substancial do provimento inibitório, mediante a imposição de condutas positivas ou negativas ao autor do ilícito.

Assim, a tutela inibitória, em sentido amplo, é dirigida contra o ilícito, a atuar na direção de obstar, evitar, prevenir a prática de ato contrário ao direito ou, quando já efetivado, impedir sua reiteração ou continuação. A tutela inibitória é consequência da antijuridicidade extraída do ordenamento jurídico, logo constitui fattispecie distinta da tutela reparatória, a qual é focada no efeito do dano (ROSENVALD, 2013, p. 35). O novo Código de Processo Civil previu as três categorias de tutela inibitória: a) tutela preventiva do ato ilícito (tutela inibitória pura); b) tutela impeditiva da reiteração do ilícito; e c) tutela impeditiva da continuação do ato ilícito (BOVINO, 2016, p. 13).

Didier Junior (2014, p. 89-95) afirma que o ideal é que o processo jurisdicional propicie sempre a tutela específica, aquela que coincide com o que determina o direito material. Ainda segundo o autor, a tutela específica se divide em três espécies: a) a tutela inibitória stricto sensu, que não se volta contra o dano, mas apenas contra o ilícito iminente; b) a tutela de remoção do ilícito, nas hipóteses em que o ilícito já foi praticado, mas não se investiga a ocorrência de dano; e c) a tutela repressiva específica, na qual se discute o dano e se pede reparação in natura, como, por exemplo, no direito de resposta eleitoral e no reflorestamento ante os danos ambientais.

O proprietário ou possuidor do imóvel possui o direito de fazer cessarem as interferências prejudiciais à sua segurança, sossego e à saúde dos habitantes, provocadas pela utilização anormal de imóvel vizinho, sendo certo que essas interferências vizinhas devem ser analisadas sob a ótica da 
natureza da utilização e localização do prédio, assim como os limites ordinários de tolerância daquele que se sente lesado (BOVINO, 2016, p. 199) ${ }^{3}$.

Sendo assim, ao proprietário ou possuidor do imóvel é garantida a via da ação inibitória como instrumento processual para não ser molestado em seu sossego domiciliar, postulando-se ao Estado-juiz que impeça a prática de ilícitos em face da inviolabilidade de seu direito à moradia. De forma mais ampla, todo aquele que se vir diante de um ilícito (ou iminência de ilícito) contra um direito de personalidade tem garantido o interesse apenas no desfazimento de situação ilícita já presente (ou no impedimento da ocorrência de ilícitos), independentemente de qualquer repercussão pecuniária.

\section{A COMPENSAÇÃO IN NATURA DE DANOS MORAIS}

No presente tópico, discute-se o emprego de meios não pecuniários para o enfrentamento dos danos morais. Após investigar a viabilidade de aplicação dessas alternativas mesmo sem autorização legal expressa, são estudados os fundamentos da compensação in natura de danos morais.

\subsection{A AUSÊNCIA DE PREVISÃO LEGAL EXPRESSA COMO ARGUMENTO SUPERÁVEL}

A dimensão fática, a par do direito legislado, revela-se imprescindível na apreciação do caso concreto: o intérprete complementa sua compreensão a partir da análise dos fatos e, nesse processo, exsurgem juízos de natureza axiológica. Sendo assim, a ciência jurídica não pode ser reduzida à mera descrição do significado dos textos, os quais constituem o ponto de partida da interpretação; tal significado não está incorporado ao conteúdo das palavras, pois depende do uso e da interpretação (ÁVILA, 2007, p. 31).

Como observa Renato José de Moraes (2017, p. 108), o direito demanda treino, para alcançar a capacidade de distinguir o que é o justo ou jurídico no caso concreto, de modo que o jurista necessita não apenas de apuro técnico, mas também conhecimento experiencial da vida, das pessoas e da sociedade.

\footnotetext{
${ }^{3}$ Veja-se, à guisa de ilustração, o seguinte julgado sobre o emprego da tutela inibitória diante de ilícito no âmbito do direito de vizinhança: "AGRAVO DE INSTRUMENTO. Direito de vizinhança. Tutela para inibir o funcionamento de área de lazer para crianças, em área contígua à unidade condominial, exposta à grave perturbação do sossego. Pleito para concessão de medida liminar. Recurso do autor. Provimento" (SÃO PAULO (Estado). Tribunal de Justiça de São Paulo. Agravo de Instrumento $\mathrm{n}^{\circ}$ 2234107-62.2017.8.26.0000. Relator: Des. Carlos Russo, Trigésima Câmara de Direito Privado, julgado em 9 maio 2018. Diário de Justiça Eletrônico. Disponível em: <https://goo.gl/Z8anpx>. Acesso em: 9 jun. 2018).
} 
Na perspectiva do direito civil constitucional, o reconhecimento da efetividade dos valores consagrados no ordenamento constitucional provocou mudanças de paradigmas em relação a institutos jurídicos clássicos e concepções jurídicas tradicionais, independentemente de modificações veiculadas por atos legislativos. Nessa esteira, são constatadas profundas alterações, como: a) a técnica legislativa passa a oferecer textura mais aberta, com a definição de objetivos, distanciando-se do ideal de estabilidade e regulação para negócios, com a ampliação no emprego de cláusulas gerais e conceitos abertos; b) passa-se a conferir maior atenção a uma função promocional do direito, e não apenas repressiva; e c) a humanização do direito abre margem para o legislador tratar não apenas de questões patrimoniais, permitindo-se a imposição de deveres extrapatrimoniais nas relações entre particulares, a fim de assegurar a personalidade e, em última análise, a tutela da dignidade humana (TEPEDINO, 2004, p. 3-5).

O sistema de responsabilidade civil baseado na culpa, acentuadamente individualista e patrimonialista, tem caminhado em direção a um sistema de reparação do dano baseado na objetivação do dever de indenizar. Tal fenômeno se lastreia no fundamento da solidariedade social (solidarité sociale), entendida como vetor axiológico derivado da consciência racional da existência de interesses em comum, a fazer exsurgir a obrigação moral de "não fazer aos outros o que não se deseja que lhe seja feito”, a partir do reconhecimento dialético do outro (MORAES, 2003, p. 111112). A solidariedade traz em si a ideia de transcendência das escolhas e das ações humanas em relação aos demais integrantes da sociedade, a evidenciar a necessidade de apoio das pessoas umas para com as outras (ARANGO, 2013, p. 49).

Outrossim, no intuito de aumentar o nível de proteção às vítimas de danos tidos como injustos, vem ocorrendo a flexibilização dos chamados filtros tradicionais da reparação, como a culpa e o nexo de causalidade, como assevera Anderson Schreiber (2009, p. 11-12). Nesse sentir, o autor propõe a utilização da técnica de ponderação de valores para selecionar o interesse jurídico merecedor de tutela em casos de responsabilidade civil, ao asseverar que

[u]m certo componente valorativo é mesmo pressuposto da ponderação na medida em que ela vem justamente se opor ao tradicional uso exclusivo da subsunção, cujo rigor metodológico não garantiu resultados concretamente mais justos no decorrer de seu longo império. Ademais, a interpretação do dado normativo, mesmo na ausência de norma específica, uma vez justificada expressamente, autoriza o controle de sua validade e de seu grau de convencimento, em um profícuo debate que, ao contrário do que ocorreria em outros campos de conhecimento, encontra-se, fatalmente, limitado por uma decisão final, intrínseca à própria estrutura judiciária e à finalidade prática do direito (SCHREIBER, 2009, p. 171173). 
Veja-se, portanto, que o direito legislado serve como um ponto de partida bastante embrionário na resolução das demandas em responsabilidade civil. Na doutrina de Kelsen (2006, p. 390-391), existiriam normas jurídicas gerais, as quais gerariam molduras de significados possíveis, e normas individuais, obtidas pelo ato volitivo do órgão jurídico na escolha de um dos significados possíveis. Já para Müller (2009, p. 244-300), a norma jurídica (norma de decisão) é construída em um processo de concretização, de modo que não há norma jurídica previamente dada ao caso concreto: a norma jurídica se estrutura a partir dos dados linguísticos referentes ao texto (programa da norma) e dos dados reais referentes ao caso concreto (âmbito da norma). Considerando que as disposições legais sobre responsabilidade civil deixam ampla margem de decisão para a concretização do direito à indenização, constata-se de forma mais evidente, nesse campo jurídico, a relevância da apreciação do âmbito da norma para a construção da norma de decisão.

Com a finalidade de compreender os atributos da norma jurídica, também se mostram úteis as lições de Gustavo Zagrebelsky (1995, p. 17-18), as quais sustentam uma concepção de direito dúctil, uma concepção dogmática fluida lastreada em um pluralismo intrínseco de valores no Estado constitucional. Ainda segundo Zagrebelsky (1995, p. 132-133), o direito deve ser tido como uma disciplina prática e bipolar, em que a interpretação jurídica consiste na busca pela norma adequada tanto ao caso como ao ordenamento, de modo que o intérprete mantém certa autonomia de um e de outro.

A respeito da responsabilidade civil, Zagrebelsky (1995, p. 125-126) alerta que a extensão excessiva da categoria do dano ressarcível em dinheiro pode criar um "mercado de valores", caracterizado pela mercantilização dos valores jurídicos; assim, a tendência tirânica de transmutação do conteúdo da Constituição (inclusive dos direitos fundamentais) em valor-dinheiro significaria a submissão indevida dos demais valores ao valor da economia, o que seria nocivo porque, numa sociedade com pluralidade de princípios e valores, deve haver uma prudente ponderação entre os valores envolvidos no caso concreto a fim de obter-se a solução justa.

Portanto, a missão de construir soluções jurídicas em casos concretos de responsabilidade civil revela-se complexa e árdua. Nesse cenário, entende-se que a mera ausência de autorização legal expressa para a compensação in natura do dano moral não constitui, por si só, argumento suficiente para afastar sua viabilidade jurídica. 


\subsection{FUNDAMENTOS PARA A COMPENSAÇÃO IN NATURA DE DANOS MORAIS}

O reconhecimento da força normativa dos princípios constitucionais e o enfoque na dignidade da pessoa humana provocaram uma radical alteração da estrutura tradicional do direito civil, diante do predomínio das situações jurídicas existenciais sobre as relações patrimoniais (MORAES, 2003, p. 234), e ensejaram a construção de nova significação ao interesse jurídico merecedor de tutela, permitindo a abertura de um leque de situações subjetivas, que superam o viés patrimonial, a que outrora se concedia proteção menos efetiva (COSTA; POMPEU, 2016, p. 7-11).

Sob a perspectiva constitucional, considerada a dimensão objetiva dos direitos fundamentais, cabe compreender um sistema de direito civil mais harmonizado com as necessidades existenciais da pessoa humana, para além de interesses meramente patrimoniais, a partir de um renovado juízo axiológico das técnicas jurídicas, das noções tradicionais e da teoria da interpretação (PERLINGIERI, 2007, p. 12).

Partindo-se da compreensão de que a axiologia constitucional expressa preocupação em promover a pessoa humana em seu aspecto ético, deslocando-se a ênfase de seus bens materiais para sua dignidade, afigura-se desarmônico enxergar na reparação pecuniária a única via para compensar a vítima do dano moral. Nos casos em que a compensação in natura se mostre viável no plano fático, cumprirá com maior eficiência sua função compensatória, em consonância com o princípio da restituição integral (restitutio in integrum). O remédio exclusivamente pecuniário para danos morais estimula nas pessoas sentimentos mercenários, sem constituir o meio mais adequado para fazer frente ao dano moral.

Cabe registrar que, embora tenha sido impulsionada à luz do direito civil constitucional, a questão da reparação in natura já havia sido enfrentada, por exemplo, por Pontes de Miranda (1970, p. 251), tendo recebido posicionamento favorável, nos seguintes termos:

Se o bem atingido não pode ser medido economicamente, como de fato não pode, e se a tônica do instituto da responsabilidade é a restituição da vítima ao estado anterior ao dano, nada mais razoável do que procurar reparar in natura, tanto quanto seja possível.

Rememore-se o episódio icônico ocorrido com a atriz francesa Brigitte Bardot em 1960, narrado por Antônio Chaves (1972, p. 68-70): a artista sofreu danos de natureza moral e requereu, na petição inicial da demanda de indenização, que o ofensor fosse condenado a pagar apenas “um franco” como reparação; ao vencer a disputa judicial, recebeu o único franco em sessão na qual os veículos midiáticos se fizeram presentes para ampla divulgação do acontecimento. Veja-se que, à época, já se notava a insuficiência dos meios jurídicos disponíveis para fazer frente à ofensa no âmbito 
extrapatrimonial, de modo que foi preciso recorrer ao artifício de requerer valor simbólico na ação judicial e contar com a divulgação da imprensa.

A compensação in natura de danos morais combate a mercantilização da responsabilidade civil. Numa sociedade em crise moral, o pragmatismo excessivo no mecanismo de reparação de danos acaba por induzir à conclusão de que a lesão a interesses jurídicos existenciais é a todos franqueada, desde que se esteja disposto a pagar o correspondente “preço”, até mesmo sob uma ótica de Análise Econômica do Direito (Law and Economics).

A associação de meios não pecuniários de compensação a danos morais também apresenta a vantagem de desestimular a conduta do ofensor, porém sem recorrer à condenação a um sobrevalor a título punitivo, ou seja, sem a importação da figura dos punitive damages, que tem recebido severas críticas por parcela da doutrina brasileira ${ }^{4}$.

Mencionem-se, ainda, as conhecidas dificuldades na quantificação do dano moral como fator que aponta a insuficiência da resposta monetária como meio de enfrentamento dos conflitos que envolvem lesões a interesses extrapatrimoniais. Nesse sentido, é salutar a busca por alternativas não pecuniárias, que, sem substituir por completo a compensação monetária, possam complementá-la, na tentativa de efetivamente reparar ou aplacar o prejuízo moral.

Pontue-se, ademais, que, no direito brasileiro, o Código Civil, em seu artigo 944, dispõe que “a indenização mede-se pela extensão do dano”, porém sem determinar expressamente que apenas a via pecuniária é possível. Aliás, mesmo na seara do dano patrimonial, os tribunais pátrios, inspirados pela consagração expressa da execução específica das obrigações em diversas passagens do Código Civil $^{5}$, têm buscado, sempre que possível, preservar a solução in natura, em detrimento da conversão da obrigação em perdas e danos (SCHREIBER, 2009, p. 195).

A reparação não pecuniária a danos extrapatrimoniais já conta com previsão legal em hipóteses específicas, como, por exemplo: a) a Lei do Direito de Resposta (Lei n. 13.188, de 11 de novembro de 2015) garante o direito de resposta ou retificação em matéria divulgada, publicada ou transmitida por veículo de comunicação social, de modo a suprir a lacuna deixada pela declaração de não recepção da antiga Lei de Imprensa pela Constituição de $1988^{6}$, sem prejuízo de que o prejudicado deduza pedido de indenização pecuniária em ação própria; b) o Código Eleitoral (artigo 243) e a Lei das Eleições (artigos 58 e 58-A) disciplinam pedidos de retratação e de concessão de direito de

\footnotetext{
${ }^{4}$ Permita-se remeter à crítica feita por Bodin de Moraes (2003, p. 195-264).

${ }^{5}$ Por exemplo, confira-se o disposto nos artigos 249, 251 e 463.

${ }^{6}$ Cf. BRASIL. Supremo Tribunal Federal. Arguição por Descumprimento de Preceito Fundamental n. 130/DF. Relator: Min. Carlos Ayres Britto, Plenário, julgado em 30 abr. 2009. Diário de Justiça Eletrônico. Disponível em: <https://goo.gl/jkOXr>. Acesso em: 20 jul. 2018.
} 
resposta no âmbito do Direito Eleitoral; e c) a Lei da Política Nacional do Meio Ambiente (artigo 4º, incisos VI e VII) estabelece ao poluidor e ao predador a obrigação de restauração ou recuperação natural como forma de reparação específica de danos ambientais; e d) a Lei do Sistema Nacional de Unidades de Conservação da Natureza (artigo $4^{\circ}$ ) apresenta objetivos relacionados atados ao ideal da reparação específica dos danos ambientais, como contribuir para a restauração da diversidade de ecossistemas naturais, recuperar recursos hídricos e edáficos, bem como recuperar ou restaurar ecossistemas degradados.

A par disso, cresce o número de decisões judiciais arrojadas, que, a despeito da ausência de autorização legal expressa, vêm empregando meios não pecuniários de compensação de danos morais. Essa diretriz foi acolhida na VII Jornada de Direito Civil do Conselho da Justiça Federal, em que a viabilidade jurídica da compensação in natura de danos extrapatrimonial foi reconhecida pelo Enunciado n. 589, sob o fundamento de que não há, no Código Civil, norma que estabeleça a indenização em dinheiro como meio exclusivo de compensação a danos morais:

ENUNCIADO 589 - A compensação pecuniária não é o único modo de reparar o dano extrapatrimonial, sendo admitida a reparação in natura, na forma de retratação pública ou outro meio ${ }^{7}$.

À guisa de ilustração, mencione-se a construção no sentido de que se mostra viável, para a reparação de danos morais, a condenação à retratação pública, que estava prevista na Lei de Imprensa (Lei n. 5.250, de 9 de fevereiro de 1967) apenas para aquele âmbito de aplicação específico. Confirase a ementa de julgado do Tribunal de Justiça do Rio Grande do Sul, a respeito de caso em que houve ofensas publicadas em vídeo postado numa rede social, tendo o tribunal mantido a condenação pecuniária em conjunto com a condenação à “elaboração de retratação pública na rede social”:

Recurso inominado. Ação indenizatória por danos morais. Fato falso imputado ao autor. Xingamentos e vídeo publicado através das redes sociais. Ofensa à honra do requerente devidamente comprovada. Art. 186 do CC/2002. Dano moral reconhecido e que ampara o pleito indenizatório. Indenização fixada em R \$ 5.000,00 e que não comporta redução porque fixada de acordo com a peculiaridade do caso em concreto. Mantida ainda a condenação à retratação pública a fim de amenizar o mal sofrido pelo requerente. Sentença confirmada. Recurso não provido ${ }^{8}$.

Schreiber (2014) registra a existência de julgados no sentido da reparação in natura de danos extrapatrimoniais, como, por exemplo: a) na Justiça do Trabalho, podem ser encontradas decisões

\footnotetext{
${ }^{7}$ BRASIL. Conselho da Justiça Federal. VII Jornada de Direito Civil [28-29 de setembro de 2015, Brasília]. Brasília: Centro de Estudos Judiciários, 2015. 109 p. Disponível em: <https://goo.gl/TvvgD8>. Acesso em: 9 jun. 2018 , p. 25.

${ }^{8}$ RIO GRANDE DO SUL. Tribunal de Justiça do Rio Grande do Sul. Recurso Cível n. 71006253462/RS. Relator: Des. Gisele Anne Vieira de Azambuja, Quarta Turma Recursal Cível, julgado em 14 out. 2016. Diário de Justiça Eletrônico. Disponível em: <https://goo.gl/mV9yqn>. Acesso em: 9 jun. 2018.
} 
que deferem não apenas condenação à indenização pecuniária ao empregado que teve seu direito trabalhista lesado por assédio moral, mas também à afixação de pedido de desculpas no local de trabalho do demandante, o que apresenta um efeito reparatório muito mais efetivo, como registra; e b) na seara do Direito do Consumidor, merece menção o caso em que um consumidor ficou sem energia elétrica em casa, por ter se recusado a pagar cobrança abusiva da concessionária, e depois obteve a condenação da demandada não apenas a pagar indenização em pecúnia, mas também a incluir, por um ano, um pedido de desculpas na conta de energia.

Ainda à guisa de ilustração, tem-se discutido a viabilidade da compensação pecuniária de danos morais decorrentes de abandono afetivo, nas hipóteses em que o pai ou a mãe não cumprem o dever de cuidado em relação ao filho, em ofensa aos seus interesses existenciais (HIRONAKA, 2010, p. 223). Nesses casos, em substituição parcial ou total da condenação em dinheiro, é possível vislumbrar como alternativa a promoção de encontros entre demandante e demandado, com o apoio da equipe multidisciplinar que auxilia o juízo, conforme as circunstâncias do caso concreto recomendem. Por exemplo, se um adolescente ingressa com uma ação dessa natureza contra o pai, a reconstrução de laços a partir daquele momento, embora não tenha o condão de modificar o passado, poderá servir para auxiliar a compensar a ausência anterior e permitir maior apoio e cuidado ao adolescente dali em diante.

Digno de nota, ainda, o exemplo do chamado "segundo abandono”, hipótese em que a criança abandonada pelos pais biológicos é adotada e o adotante vem a expressar a intenção de voltar atrás, momento em que a criança é abandonada pela segunda vez. Nesses casos, em substituição total ou parcial da condenação pecuniária do adotante por danos morais, pode-se discutir a possibilidade de conceder àquela criança prioridade na lista de adoção, para que a reparação se dirija a combater precisamente aquilo que mais a aflige (BARRETO; MENEZES, 2016, p. 189-206).

No próprio âmbito do Supremo Tribunal Federal, em julgamento de 2017, houve três votos que buscaram resolver a demanda de danos morais por via não pecuniária. Trata-se do Recurso Extraordinário n. 580.252/MS, no regime de repercussão geral, em que o tribunal concluiu que o preso submetido a situação degradante e a superlotação na prisão tem direito a indenização do Estado por danos morais ${ }^{9}$. Houve diferentes posições entre os ministros quanto à reparação a ser adotada,

\footnotetext{
${ }^{9}$ O Plenário aprovou também a seguinte tese, para fim de repercussão geral: “Considerando que é dever do Estado, imposto pelo sistema normativo, manter em seus presídios os padrões mínimos de humanidade previstos no ordenamento jurídico, é de sua responsabilidade, nos termos do artigo 37, parágrafo $6^{\circ}$, da Constituição, a obrigação de ressarcir os danos, inclusive morais, comprovadamente causados aos detentos em decorrência da falta ou insuficiência das condições legais de encarceramento” (BRASIL. Supremo Tribunal Federal. Recurso Extraordinário n. 580.252/MS. Relator p/ acórdão: Min. Gilmar Mendes, Plenário, julgado em 16 fev. 2017. Diário de Justiça Eletrônico. Disponível em: <https://goo.gl/gTeFBo>. Acesso em: 9 jun. 2018).
} 
tendo vencido a corrente pela indenização em dinheiro e parcela única. Sem embargo, proposta feita pelo ministro Luís Roberto Barroso substituía a indenização em dinheiro pela remição da pena, com redução dos dias de prisão proporcionalmente ao tempo em situação degradante. Esse entendimento foi seguido pelos ministros Luiz Fux e Celso de Mello, tendo este último destacado que a entrega de uma indenização em dinheiro conferiria resposta pouco efetiva aos danos morais sofridos pelos detentos, bem como drenaria recursos escassos que poderiam ser aplicados no próprio sistema carcerário.

Em suma, observa-se a gradual abertura da doutrina e dos tribunais brasileiros a outras alternativas que se somam à indenização pecuniária do dano extrapatrimonial, como o pedido de desculpas público ou outros meios considerados adequados no caso concreto.

\section{CONCLUSÃO}

O conflito vivenciado pela protagonista Clara no filme Aquarius apresenta força expressiva e simbólica apta a estimular no jurista uma experiência estética capaz de fazer compreender que, em determinadas situações da vida, o dinheiro tem pouca relevância. Qualquer tentativa de apenas estabelecer vantagem pecuniária em favor de Clara não seria capaz de tutelar efetivamente seu direito: para a personagem, importava apenas uma resposta jurídica que lhe garantisse o mínimo para uma existência digna e pacífica dentro de seu próprio domicílio.

Nesse diapasão, o tradicional pensamento voltado ao aspecto repressivo da responsabilidade civil, com o dever de compensar os danos morais, deve ser ponderado com a tendência contemporânea da atuação preventiva do direito no sentido da preservação e efetiva tutela dos direitos da personalidade, com o propósito de evitar a ocorrência do dano, a demonstrar a importância da tutela específica nos tempos atuais. Assim, ao proprietário ou possuidor do imóvel é garantida a via da ação inibitória como instrumento processual para não ser molestado em seu sossego domiciliar, para requerer judicialmente o impedimento da prática de ilícitos em face da inviolabilidade de seu direito à moradia.

Ainda, constatou-se na presente pesquisa a existência de decisões judiciais mais arrojadas, que, a despeito da ausência de autorização legal expressa, vêm empregando meios não pecuniários de compensação de danos morais. Nesse sentir, entende-se salutar o aprofundamento do debate sobre a busca por alternativas não pecuniárias, que, sem substituir por completo a compensação monetária, possam complementá-la, na tentativa de conferir resposta efetiva aos prejuízos morais. Afinal, considerando que a ordem constitucional expressa preocupação em promover a pessoa humana em 
seu aspecto ético, reputa-se desarmônico enxergar na reparação pecuniária o único meio de satisfazer a vítima dos danos morais.

De volta ao mote do filme Aquarius, pode-se especular que a personagem Clara teria pouco ou nenhum interesse na compensação pecuniária pelos danos morais que sofreu. Já no fim da vida e tendo amealhado considerável patrimônio em razão do seu sucesso profissional, a indenização em dinheiro, isoladamente, representaria para ela nova humilhação diante da construtora que tanto perturbou sua paz de espírito e seu sossego domiciliar com o emprego de expedientes vis.

Cabe ao jurista refletir sobre a possibilidade de assegurar a Clara - e a tantas Claras da vida real - a obtenção de uma determinação judicial de retratação pública ou outros meios de reparação despecuniarizados, para fazer frente a ofensas morais. Desse modo, a decisão judicial, afastando-se do enfoque monetário, alcançará o caráter pedagógico e dissuasório da condenação, além de apresentar a vantagem de centrar a resposta jurídica no campo da dignidade e da honra, que é a mesma seara em que ocorreram os danos morais.

\section{REFERÊNCIAS}

AQUARIUS. Direção: Kleber Mendonça Filho. Produção: Emilie Lesclaux; Saïd Ben Saïd; Michel Merkt. Coprodução: Walter Salles. Roteiro: Kleber Mendonça Filho. Brasil; França: CinemaScópio; SBS Productions; Videofilmes; Globo Filmes; 2016. 145 min. Dolby Digital, Color, DCP.

ARANGO, Rodolfo. Solidaridad, democracia y derechos. Revista de Estudios Sociales, Bogotá, Colômbia, n. 46, p. 43-53, maio/ago. 2013. ISSN 0123-885X. Disponível em: <https://goo.gl/P7nH3h>. Acesso em: 3 jun. 2018. DOI: http://doi.org/10.7440/res46.2013.05.

ARENHART, Sérgio Cruz. Perfis da tutela inibitória coletiva. São Paulo: RT, 2003.

ATIYAH, Patrick. The damages lottery. Oxford: Hart, 1997.

ÁVILA, Humberto. Teoria dos princípios: da definição à aplicação dos princípios jurídicos. 7. ed. ampl. e atual. São Paulo: Malheiros, 2007.

BARRETO, Júlia d'Alge Mont'Alverne; MENEZES, Joyceane Bezerra de. Segundo abandono: o que fazer quando o adotante desiste do filho que escolheu? Entre o melhor interesse da criança, a perda do poder familiar e a preservação do dever alimentar. In: XXV Congresso Nacional do CONPEDI: Direito de família e sucessões I. Org.: CONPEDI/UNICURITIBA. Florianópolis: CONPEDI, 2016. Disponível em: <https://goo.gl/cin2Lw>. Acesso em: 3 jun. 2018.

BOVINO, Marcio Lamonica. A ação inibitória enquanto tutela diferenciada autônoma. 2016. 246 f. Tese (Doutorado) - Programa de Pós-graduação em Direito da Pontifícia Universidade Católica de São Paulo, São Paulo. Disponível em: <https://goo.gl/xNmGtK>. Acesso em: 20 jul. 2018. 
BRASIL. Código Civil (2002). Lei n. 10.406, de 10 de janeiro de 2002. Disponível em: <https://goo.gl/PUmcKK>. Acesso em: 3 jun. 2018.

BRASIL. Código de Processo Civil (2015). Lei n. 13.105, de 16 de março de 2015. Disponível em: $<$ https://goo.gl/vZ0d0U>. Acesso em: 3 jun. 2018.

BRASIL. Código Eleitoral (1965). Lei n. 4.737, de 15 de julho de 1965. Disponível em: <https://goo.gl/mtsiVC>. Acesso em: 20 jul. 2018.

BRASIL. Conselho da Justiça Federal. VII Jornada de Direito Civil [28-29 de setembro de 2015, Brasília]. Brasília: Centro de Estudos Judiciários, 2015. 109 p. Disponível em: <https://goo.gl/TvvgD8>. Acesso em: 9 jun. 2018.

BRASIL. Constituição da República Federativa do Brasil (1988). Disponível em: <https://goo.gl/3Dm950>. Acesso em: 3 jun. 2018.

BRASIL. Lei da Política Nacional do Meio Ambiente. Lei n. 6.938, de 31 de agosto de 1981. Disponível em: <https://goo.gl/L1YXP6>. Acesso em: 20 jul. 2018.

BRASIL. Lei das Eleições. Lei n. 9.504, de 30 de setembro de 1997. Disponível em: <https://goo.gl/zCxzv2>. Acesso em: 20 jul. 2018.

BRASIL. Lei de Imprensa. Lei n. 5.250, de 9 de fevereiro de 1967. Disponível em: $<$ https://goo.gl/rHJsL9>. Acesso em: 20 jul. 2018.

BRASIL. Lei do Direito de Resposta. Lei n. 13.188, de 11 de novembro de 2015. Disponível em: $<$ https://goo.gl/c78K5H>. Acesso em: 20 jul. 2018.

BRASIL. Lei do Sistema Nacional de Unidades de Conservação da Natureza. Lei n. 9.985, de 18 de julho de 2000. Disponível em: <https://goo.gl/PcXf8G>. Acesso em: 20 jul. 2018.

BRASIL. Supremo Tribunal Federal. Arguição por Descumprimento de Preceito Fundamental n. 130/DF. Relator: Min. Carlos Ayres Britto, Plenário, julgado em 30 abr. 2009. Diário de Justiça Eletrônico. Disponível em: <https://goo.gl/jkOXr>. Acesso em: 20 jul. 2018.

BRASIL. Supremo Tribunal Federal. Recurso Extraordinário n. 580.252/MS. Relator p/ acórdão: Min. Gilmar Mendes, Plenário, julgado em 16 fev. 2017. Diário de Justiça Eletrônico. Disponível em: <https://goo.gl/gTeFBo>. Acesso em: 9 jun. 2018.

CESTARI, Roberto; NOJIRI, Sergio. Interdisciplinaridade: o que o direito pode aprender com o cinema. In: XXIV Encontro Nacional do CONPEDI: Direito, arte e literatura. Org.: CONPEDI/UFS. Florianópolis: CONPEDI, 2015. Disponível em: <https://goo.gl/LKYG62>. Acesso em: 3 jun. 2018.

CHAVES, Antônio. Direito à própria imagem. Revista da Faculdade de Direito da Universidade de São Paulo, São Paulo, SP, Brasil, v. 67, p. 45-75, 1972. Disponível em: <https://goo.gl/e4JXRt>. Acesso em: 9 jun. 2018. 
COSTA, Adriano Pessoa da; POMPEU, Gina Vidal Marcílio. Corte Interamericana de Direitos Humanos e desmonetarização da responsabilidade civil. Civilistica.com, Rio de Janeiro, ano 5, n. 2, p. 1-20, 2016. Disponível em: <https://goo.gl/Ekcpu1>. Acesso em: 3 jun. 2018.

DIDIER JUNIOR, Fredie. Tutela jurisdicional específica e as relações trabalhistas. Revista TST, Brasília, DF, Brasil, v. 80, n. 1, p. 88-100, jan./mar. 2014.

GIDDENS, Anthony. As consequências da modernidade. Trad. Raul Fiker. São Paulo: UNESP, 1991.

HIRONAKA, Gisela Maria Fernandes Novaes. Os contornos jurídicos da responsabilidade afetiva na relação entre pais e filhos - além da obrigação legal de caráter material. In: EHRHARDT JÚNIOR, Marcos; ALVES, Leonardo Barreto Moreira (Coord.). Leituras complementares de direito civil: direito das famílias. Salvador: Jus Podivm, 2010. p. 209-236.

HUNGRIA, Nelson. Comentários ao Código Penal. Rio de Janeiro: Forense, 1958. v. IV.

KAMIR, Orit. Why 'Law-and-Film' and what does it actually mean? A perspective. Continuum: Journal of Media \& Cultural Studies, Londres, Reino Unido, v. 19, n. 2, p. 255-278, jun. 2005.

KELSEN, Hans. Teoria pura do direito. Trad. João Baptista Machado. 7. ed. São Paulo: Martins Fontes, 2006.

MARINONI, Luiz Guilherme. Técnica processual e tutela de direitos. São Paulo: RT, 2004.

MARINONI, Luiz Guilherme. Tutela inibitória: individual e coletiva. 4. ed. São Paulo: RT, 2006.

MARTINEZ, Renato de Oliveira. Direito e Cinema no Brasil: perspectivas para um campo de estudo. 2015. 194 f. Dissertação (Mestrado) - Programa de Pós-Graduação em Direito da Universidade Federal de Santa Catarina, Florianópolis. Disponível em: <https://goo.gl/6uvH9j>. Acesso em: 20 jul. 2018.

MIRANDA, Pontes de. Tratado de direito privado. Rio de Janeiro: Forense, 1970. t. LII.

MORAES, Maria Celina Bodin de. Danos à pessoa humana: uma leitura civil-constitucional dos danos morais. Rio de Janeiro: Renovar, 2003.

MORAES, Renato José de. Que tipo de saber é o direito? Entre a ciência, a prudência e a técnica. Revista da Faculdade de Direito UFPR, Curitiba, PR, Brasil, v. 62, n. 1, p. 83-111, jan./abr. 2017. ISSN 2236-7284. Disponível em: <https://goo.gl/kiyTso>. Acesso em: 3 jun. 2018. DOI: http://dx.doi.org/10.5380/rfdufpr.v62i1.47451.

MÜLLER, Friedrich. Teoria estruturante do direito. Trad. Peter Naumann, Eurides Avance de Douza. 2. ed. São Paulo: Revista dos Tribunais, 2009.

PERLINGIERI, Pietro. Perfis do direito civil: introdução ao direito civil constitucional. Trad. Maria Cristina de Cicco. 3. ed. Rio de Janeiro: Renovar, 2007. 
REICHMAN, Amnon. The production of law (and cinema): Preliminary comments on an emerging discourse. Southern California Interdisciplinary Law Journal, Los Angeles, Estados Unidos, v. 17, n. 3, p. 457-508, spring 2008. Disponível em: <https://goo.gl/K3XGTQ>. Acesso em: 9 jun. 2018.

RIO GRANDE DO SUL. Tribunal de Justiça do Rio Grande do Sul. Recurso Cível n. 71006253462/RS. Relator: Des. Gisele Anne Vieira de Azambuja, Quarta Turma Recursal Cível, julgado em 14 out. 2016. Diário de Justiça Eletrônico. Disponível em: <https://goo.gl/mV9yqn>. Acesso em: 9 jun. 2018.

ROSENVALD, Nelson. As funções da responsabilidade civil: a reparação e a pena civil. São Paulo: Atlas, 2013.

SÃO PAULO (Estado). Tribunal de Justiça de São Paulo. Agravo de Instrumento $\mathrm{n}^{\circ}$ 223410762.2017.8.26.0000. Relator: Des. Carlos Russo, Trigésima Câmara de Direito Privado, julgado em 9 maio 2018. Diário de Justiça Eletrônico. Disponível em: <https://goo.gl/Z8anpx>. Acesso em: 9 jun. 2018.

SCHREIBER, Anderson. Novos paradigmas da responsabilidade civil. 2. ed. São Paulo: Atlas, 2009.

SCHREIBER, Anderson. Novos paradigmas da responsabilidade civil. In: Perfil da responsabilidade civil contemporânea (congresso). Tribunal Superior do Trabalho. Brasília, 11 de novembro de 2014. Disponível em: <https://goo.gl/vN4vtU>. Acesso em: 3 jun. 2018.

SILVA JUNIOR, Walter Nunes da. Curso de direito processual penal: teoria (constitucional) do processo penal. Rio de Janeiro: Renovar, 2008.

SOUZA, Sérgio Iglesias Nunes de. Direito à moradia e de habitação: análise comparativa e suas implicações teóricas e práticas com os direitos da personalidade. 2. ed. São Paulo: RT, 2009.

TEPEDINO, Gustavo. Temas de direito civil. 3. ed. rev. e atual. Rio de Janeiro: Renovar, 2004.

VILLAÇA, Pablo. Aquarius. Crítica. Nota: 5/5. 17 maio 2016. Disponível em: $<$ https://goo.gl/YqivP1>. Acesso em: 3 jun. 2018.

XEREZ, Rafael Marcílio. Concretização dos direitos fundamentais: teoria, método, fato e arte. Rio de Janeiro: Lumen Juris, 2014.

ZAGREBELSKY, Gustavo. El derecho dúctil: ley, derechos y justicia. Trad. Marina Garcón. Madrid: Trotta, 1995. Graduação em Direito Constitucional (Mestrado e Doutorado) e de Graduação em Direito da Universidade de Fortaleza. Juiz Titular da $2^{\text {a }}$ Vara do Trabalho de Fortaleza. E-mail: rafaelmx@unifor.br 


\section{Márcio Anderson Silveira Capistrano}

Graduado (2010) em Direito pela Universidade Federal do Ceará e Mestrando no Programa de Pós-Graduação em Direito Constitucional da Universidade de Fortaleza, com bolsa da Fundação Cearense de Apoio ao Desenvolvimento Científico e Tecnológico (Funcap). Advogado da União lotado na Consultoria Jurídica junto ao Ministério da Integração Nacional em Brasília. E-mail: marcioandersonsc@gmail.com 